\title{
PKU BAGI GURU BK SMK KABUPATEN MAGELANG UNTUK OPTIMALISASI KOMPETENSI, KINERJA DAN LAYANAN GURU BK BERBASIS FLOP SMART
}

\author{
Hijrah Eko Putro ${ }^{1}$, Tawil ${ }^{2}$ \\ ${ }^{1,2}$ Bimbingan Konseling, Fakultas Keguruan dan Ilmu Pendidikan \\ Universitas Muhammadiyah Magelang \\ Email: hijrah.ekoputro@ummgl.co.id
}

\begin{abstract}
University partnership program aims to: (1) enhance the quality, performance and service teacher BK in the school environment; (2) Improving the competence of teachers BK in carrying out guidance and counseling services to students; (3) Increase of innovations in managing the administration of BK-based smart flop.University partnership program was conducted in the laboratory of the Faculty of Economics and business Internet Muhammadiyah University of Magelang, on December 13-14 March 2019. Trainees are teachers BK CMS in Magelang Regency. In order to achieve the goals that have been mentioned before, then taken steps as follows: (1) contact the headteacher and Chair of guidance counseling Teacher Magelang to know the extent to which teachers utilize smart looking and flop analysis data related training needed in increasing competence, service and performance teacher BK through the analysis of a smart flop; (2) organized a training program that includes the stage introduction, the training phase, and the phase of evaluation results; (3) the stage of introduction and training is done in groups.Based on the results of the University partnership program can be concluded: (1) this activity can improve the understanding and skill in the use of a smart flop analysis; (2) these activities are able to improve and optimize the performance of teacher competence, BK in providing guidance and counselling services in particular related patterns service BK to the students; (3) the activity is able to foster a spirit of improvements to independently by utilizing technology-based smart flop.
\end{abstract}

Keywords: Competence, Performance, Smart Flop

\begin{abstract}
Abstrak. Program kemitraan universitas ini bertujuan untuk: (1) Meningkatkan layanan, kinerja dan kualiatas guru BK di lingkungan sekolah; (2) Meningkatkan kompetensi guru BK dalam melaksanakan layanan bimbingan dan konseling kepada siswa; (3) Menambah inovasi dalam mengelola administrasi BK berbasis flop smart (from laptop to smartphone).Program kemitraan universitas ini dilaksanakan di Laboratorium Internet Fakultas Ekonomi dan Bisnis Universitas Muhammadiyah Magelang, pada tanggal 13-14 Maret 2019. Peserta pelatihan adalah guru BK SMK di Kabupaten Magelang. Dalam rangka mencapai tujuan yang telah disebutkan sebelumnya, maka ditempuh langkah-langkah sebagai berikut: (1) Menghubungi Kepala Sekolah dan Ketua Musyawarah Guru Bimbingan Konseling untuk mengetahui sejauh mana guru memanfaatkan analisis flop smart (from laptop to smartphone). dan mencari data terkait pelatihan yang dibutuhkan dalam peningkatan kompetensi, layanan dan kinerja guru BK melalui analisis flop smart (from laptop to smartphone); (2) Menyelenggarakan program pelatihan yang meliputi tahap pengenalan, tahap pelatihan, dan tahap evaluasi hasil; (3) Tahap pengenalan dan pelatihan dilakukan secara kelompok.Berdasarkan hasil program kemitraan universitas dapat disimpulkan: (1) Kegiatan ini dapat meningkatan pemahaman dan keterampilan dalam penggunaan analisis flop smart (from laptop to smartphone), (2) Kegiatan ini mampu meningkatan dan mengoptimalkan kompetensi, kinerja guru BK dalam memberikan layanan bimbingan dan konseling khususnya terkait pola pelayanan BK kepada siswa. (3) Kegiatan ini mampu menumbuhkan semangat dalam peningkatan kinerja secara mandiri dengan memanfaatkan teknologi berbasis flop smart (from laptop to smartphone).
\end{abstract}

Kata kunci : Kompetensi, Kinerja, Flop Smart

\section{PENDAHULUAN}

Latar belakang dilakukannya program kemitraan universitas di lingkungan Sekolah Menengah Kejuruan dengan sasaran para guru BK adalah berawal dari kegelisahan Guru BK dalam memberikan pelayanan kepada siswa dalam hal manajemen dan administrasi terkait pelayanan bimbingan dan konseling yang ada disekolah. Para guru BK jarang sekali atau bahkan tidak sama sekali menggunakan instrumen data khususnya aplikasi yang berkaitan dalam IT berbasis flop smart sehingga ditemukan banyak guru masih menggunakan metode konvensional dan manual, baik cara memberikan layanan klasikal dan juga pengadminitrasian terutama berbasis flop smart dapat diartikan 
sebagai suatu metode atau teknik untuk proses pemberian layanan klasikal serta model pengadministrasian data BK dari laptop yang dikonfersikan ke Smartphone.

Pentingnya kinerja Guru BK dalam pemanfaatan aplikasi komputer dalam rangka proses pembelajaran dan kompetensi guru BK, karena pada hakikatnya pelayanan kepada peserta didik tidak hanya secara klasikal saja tetapi juga harus tersedia alat instrumen pendukung dalam bentuk flop smart. program kemitraan universitas ini bertujuan untuk meningkatkan kompetensi guru BK melalui pelayanan bimbingan konseling melalui IT berbasis flop smart .

Persoalan yang dihadapi baik dari sisi situasi, SDM maupun dari sisi Manajemen selama ini adalah :

1. Belum ada sosialisasi (workshop) tentang peningkatan kompetensi dan kinerja guru BK melalui layanan bimbingan konseling menggunakan metode flop smart.

2. Terbatasnya sumber dana yang ada di mitra

3. Pelayanan yang diberikan oleh Guru BK masih kurang maksimal, serta tidak mengikuti perkembangan jaman.

4. Semangat guru BK dalam mengembangkan inovasi pelayanan BK serta administrasi instrumen data kepada siswa maupun orang tua masih kurang maksimal

5. Proses pelayanan BK masih bersifat konvensional dan manual.

Dari hasil telaah permasalahan yang dihadapi, maka tujuan serta solusi yang dapat untuk menyelesaiakan permasalahan yang ada adalah mengoptimalkan kompetensi dan kinerja guru BK dalam pelayanan bimbingan dan konseling melalui ICT berbasis flop smart yang mencakup :

1. Membuat rancangan agar dalam memberikan pelayanan terhadap siswa lebih optimal serta lebih sistematis.

2. Sebagai alat untuk mengadminitrasikan data secara komprehensif.

3. Membentuk sekelompok Guru BK SMK yang mandiri secara kompetensi dan kinerja Guru BK.

4. Peningkatan mutu Guru BK.

5. Peningkatan keterampilan dan kreativitas guru BK.
6. Guru dapat membuat dan menyajikan materi ajar. Materi bisa berupa google form dan barcode generator

Dari hasil telaah permasalahan yang dihadapi, maka solusi yang dapat diusulkan untuk menyelesaiakan permasalahan yang ada adalah Analisis flop smart dalam meningkatkan kompetensi, kinerja dan layanan bimbingan konseling Guru BK SMK Kabupaten Magelang. luaran ini mencakup :

1. Modul ICT berbasis flop smart yang nantinya bisa digunakan oleh peserta pelatihan agar bisa ditransformasikan dalam pelayanan yang lebih optimal ataupun untuk kegiatan-kegiatan pendukung lainnya.

2. Peningkatan kompetensi \& ketrampilan Guru BK SMK Kabupaten Magelang.

3. Guru BK dapat mengaplikasikan secara efektif dan efisien agar dalam adminitrasi BK lebih terstruktur.

4. Guru BK dapat mengolah data terkait tugas perkembangan siswa melalui program Analisis flop smart.

5. Melakukan pendampingan \& Evaluasi secara terstruktur kepada Guru BK

6. Guru dapat memberikan pelayanan kepada siswa dan orang tua terkait perkembangan siswa secara sistematis.

Kemukakan tujuan program dan kegunaan program serta target dan luaran. [Times New Roman, 11, spasi 1.15].

\section{METODE PELAKSANAAN}

Metode yang digunakan yaitu melalui pelatihan (simulasi) kompetensi Guru BK melalui IT berbasis flop smart. Tahapannya meliputi perencaaan, pelaksanaan, pengamatan dan evaluasi. Target khusus yang ingin dicapai yaitu guru BK dapat meningkatkan kinerja melalui melalui IT berbasis flop smart. Sehingga peran guru BK dapat diakui oleh masyarakat maupun siswa itu sendiri serta adanya luaran publikasi di jurnal pengabdian nasional yang nantinya dapat digunakan sebagaimana mestinya. Untuk memudahkan monitoring, pembagian tugas dan tanggungjawab antara pengusul dengan Mitra, rencana kegiatan pada gambar berikut. 


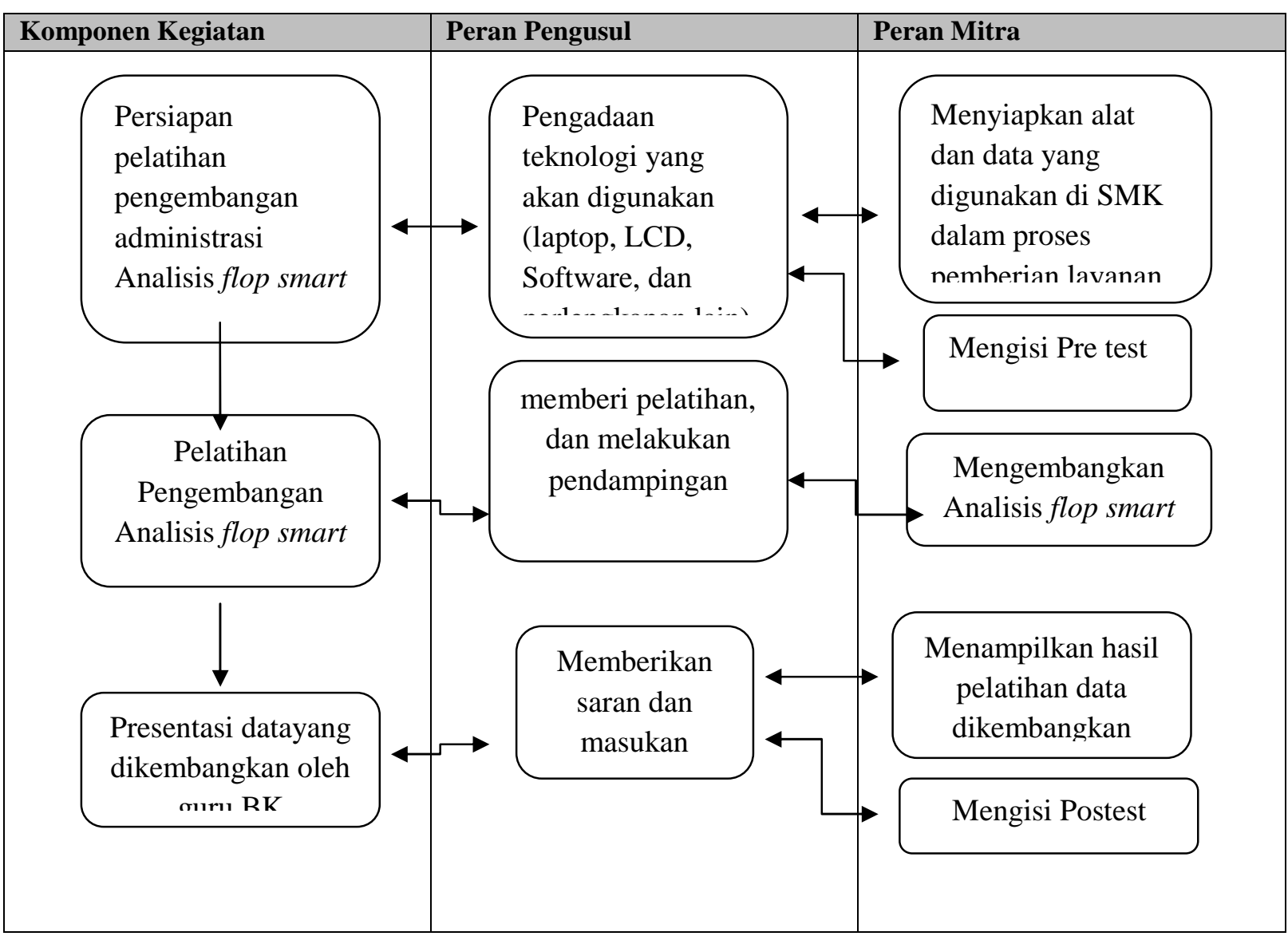

\section{Gambar 1 Rencana kegiatan pelaksanaan PKU}

Metode kegiatan ini meliputi ceramah, praktek pelatihan (Simulasi) dan diskusi serta konsultasi. Secara rinci metode yang dapat diuraikan adalah sebagai berikut:

a. Pengenalan perangkat lunak bantu yang dapat digunakan untuk membuat media pembelajaran sederhana, pengolahan dokumen dan administrasi nilai.

b. Metode praktek untuk pelatihan membuat media pembelajaran sederhana, pengolahan dokumen dan administrasi bimbingan dan konseling. c. Metode konsultasi selama pelatihan untuk membahas permasalahan yang timbul dalam pengolahan dokumen dan administrasi bimbingan konseling.

d. Metode praktek untuk pelatihan Analisis flop smart.

e. Metode konsultasi selama pelatihan untuk membahas permasalahan yang timbul dalam pelatihan Analisis flop smart.

Tabel 1. Materi Pelatihan (Simulasi) pelatihan Analisis flop smart bagi-bagi guru BK SMK dan Tahapan Pelaksanaan

\begin{tabular}{l|l|l|} 
No & Materi & Jumlah Jam \\
\hline 1 & Need Assesment (pengolahan dokumen) dengan Google Form & 4 jam \\
\hline 2 & Pengolahan data menggunakan AKPD & 4 jam \\
\hline 3 & Pembuatan media pembelajaran dengan Barcode Generator & 4 jam \\
\hline 4 & Diagram Grafik \& Focus Group Discussion ( FGD ) & 4 jam \\
\hline & Total & 16 Jam \\
\hline
\end{tabular}




\section{HASIL DAN PEMBAHASAN}

Dalam Pelaksanaan kegiatan dilakukan selama 2 Hari, kemudian rancangan metode atau pemecahan masalah tim pengusul Metodologi pemecahan masalah yang akan dilakukan yaitu dengan melaksanakan evaluasi kegiatan menggunakan metode angket pretest dan posttest, sehingga mendapatkan gambaran terkait kompetensi dan penguasaan materi pelatihan Analisis flop smart sebelum pelatihan dan sesudah pelatihan. Alur metode evaluasi bagi Guru BK SMK adalah :

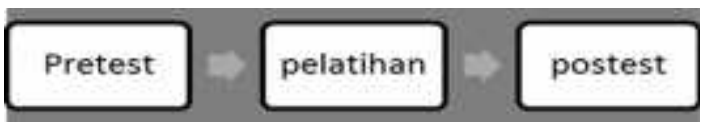

Pelaksanaan kegiatan PKU diawali dengan mengirimkan surat undangan kepada Kepala sekolah di SMK Kabupaten Magelang total sejumlah 15 sekolah dengan setiap sekolah diwakili oleh seorang guru BK. Disamping itu juga kami juga melibatkan mahasiswa sebagai pendamping Guru BK, sehingga tetap ada kesinambungan dalam menyebarluaskan pentingnya Analisis flop smart bagi Guru BK. Guru-guru yang telah mengirimkan biodata diri dan kuisioner google formulir kembali kepada tim PKU sekaligus mendaftar sebagai peserta pelatihan ada 13 Guru BK.

Kegiatan pelatihan dilaksanakan selama 2 hari, pada tanggal 13 Maret 2019 sd 14 Maret 2019. Bertempat di Laboratorium Internet FEB UMMgl, selama kurang lebih 8 jam, dari jam 08.00-16.00 WIB, dengan diikuti oleh 13 guru BK SMK di Kabupaten Magelang dan 3 Mahasiswa Program Studi BK yang membantu dalam pelaksanaan pelatihan. Dalam pelaksanaan pelatihan, diadakan pengekplorasian fitur-fitur dalam Analisis flop smart yang telah dikenal guru (antara lain google Form, Barcode Generator untuk mengakomodasi kebutuhan guru sesuai dengan kategori di atas.

Pada Sesi pertama diawali dengan membagikan pretest kepada para peserta untuk mengetahui kemampuan awal pengoperasian database sehingga tim dapat menyesuaikan sesuai tingkat kemahiran dan kemampuan para peserta.

Tabel 2. Hasil Pretest Kegiatan Pelatihan

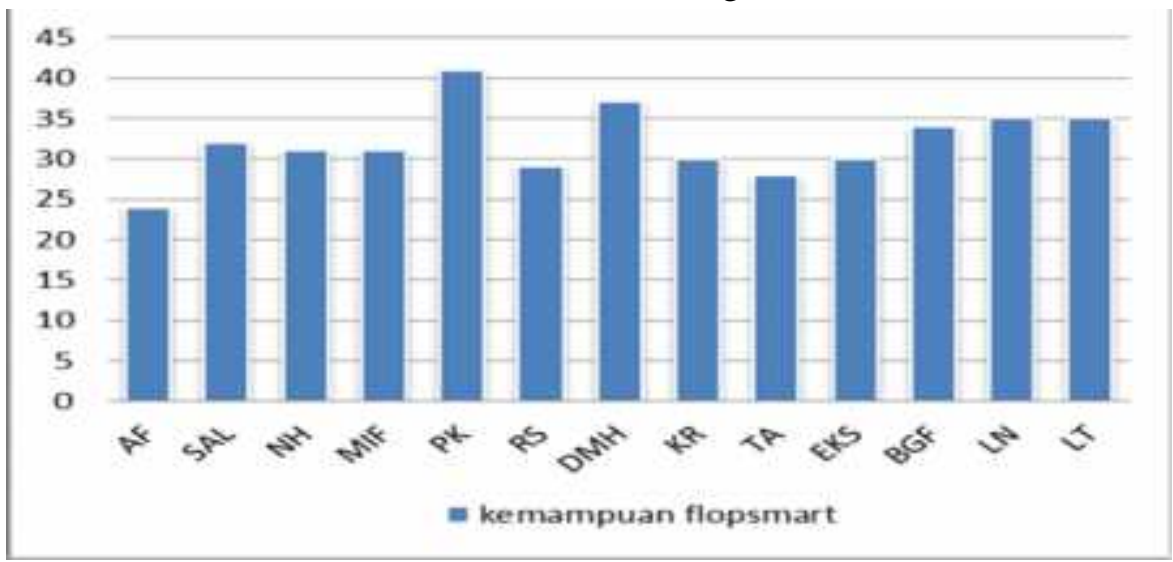

Berdasarkan data di atas, maka dapat disimpulkan bahwa persentase peserta yang terbiasa menggunakan flop smart dalam menunjang kegiatan pembelajaran dikategorikan sedang. Namun sebagian besar peserta memiliki motivasi yang sangat tinggi untuk belajar dan dapat menggunakan aplikasi komputer sebagai alat bantu maupun inovasi dalam proses belajar mengajar.

Setelah pengisian angket selesai, kegiatan dilanjutkan dengan memberikan pemahaman awal tentang materi yang akan disampaikan. Hal ini dilakukan untuk menambah wawasan guru terkait aplikasi apa yang sedang up to date saat ini dan memberikan motivasi kepada guru agar mau belajar dan menerapkan aplikasi ini.

Pada sesi pertama ini peserta dilatih dalam memaksimalkan pemanfaatan flop smart sebagai sarana untuk mengaplikasikan google form. Peserta pelatihan diminta membut administrasi data terkait yang itu digunakan 
sebagai sarana pendukung dalam mengaplikasikan flop smart. Sesi pertama dilaksanakan sekitar 4 jam dengan hasil yang baik setiap peserta mampu membuat kuisioner menggunakan google form sebagai sarana pendukung dalam analisis flop smart.

Sesi kedua, pelatihan diisi dengan materi optimalisasi fitur AKPD untuk pendukung proses pemberian layanan. Dalam sesi ini, peserta pelatihan diajak untuk mengeksplorasi fasilitas menu AKPD.

Sesi ketiga, disampaikan materi pembelajaran inovatif menggunakan barcode generator. Peserta dikenalkan dengan cara memasukkan mengoperasikan BG beserta fiturfitur yang ada didalamnya beserta aplikasi penggunaan dalam Layanan BK. Dalam setiap sesi, saat satu anggota bertugas menyampaikan materi, anggota tim yang lain mendampingi peserta pelatihan dan memberikan penjelasan per individu sehingga kesulitan yang dihadapi oleh peserta dapat segera diatasi, sehingga waktu yang digunakan menjadi lebih optimal.

Pada akhir sesi ke empat, tim PKU membagikan angket evaluasi/ posttest pelaksanaan. Angket berupa pertanyaan terbuka untuk mengetahui hasil kemampuan peserta serta pendapat peserta tentang pelaksaan kegiatan guna perbaikan kegiatan sejenis di masa mendatang. Adapun hasil Hasil Evaluasi Posttest terhadap kegiatan pelatihan disajikan dalam Tabel.

Tabel 3. Hasil Posttest Kegiatan Pelatihan

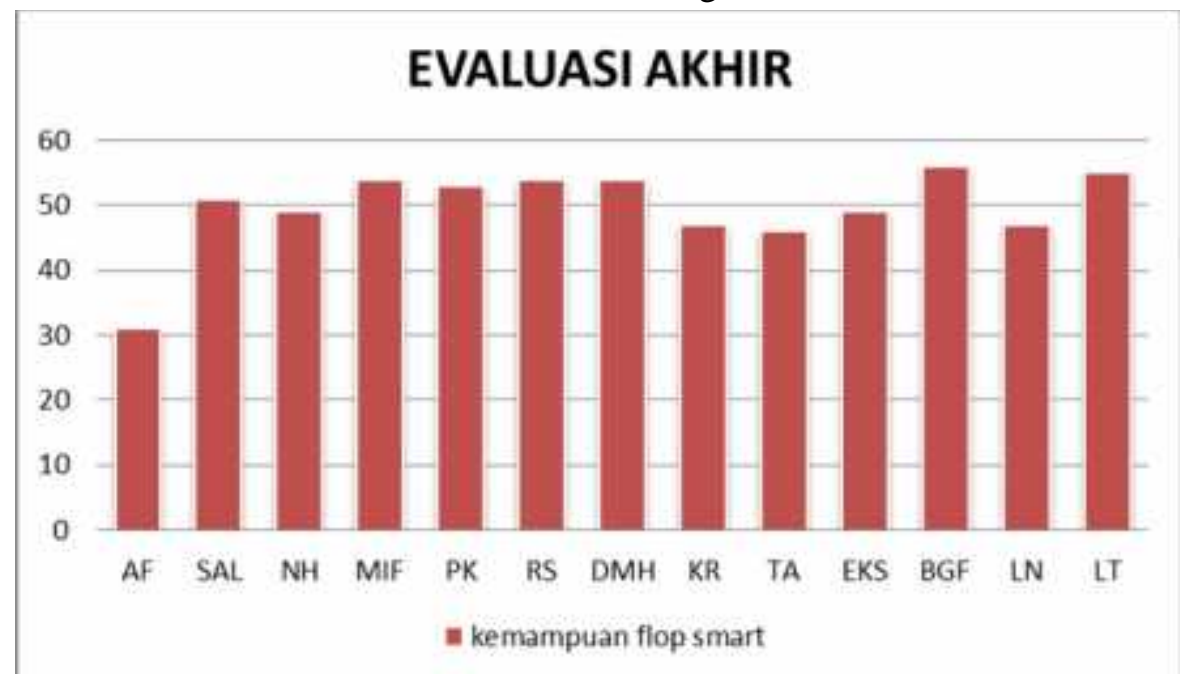

Kegiatan evaluasi dilaksanakan dalam rangka mengetahui tingkat pemahaman peserta terhadap kegiatan yang sudah dilaksanakan. Kegiatan ini dilaksanakan dengan metode angket. Peserta diminta mengisi beberapa angket yang sudah disediakan. Kemudian peserta juga diminta memberikan masukan/saran dari rangkaian kegiatan yang sudah dilaksanakan.

Ketercapaian pelatihan ini diukur dengan keberhasilan peserta dalam mengaplikasikan analisis flop smart yang telah terkomputerisasi beserta pengembangannya. Dalam hal ini, peserta pelatihan telah mampu membuat analisis analisis flop smart menggunakan aplikasi software. Peserta diberikan soal pretest, untuk mengetahui kemampuan sebelum pelatihan, setiap peserta wajib mengikuti evaluasi melalui ujian praktik atau posttest setelah pelatihan berakhir.

Secara garis besar kegiatan ini menunjukkan bahwa target luaran telah terpenuhi. Peserta mampu meningkatkan dalam penguasaan menggunakan komputer untuk mendukung proses pemberian yang terkait Penguasaan ketrampilan komputer yang dibutuhkan dalam pengaplikasikan layanan BK berbasis analisis flop smart.

Kegiatan ini dapat disempurnakan dengan pemberian pelatihan dan pengembangan lebih lanjut, terutama bagi guru BK sehingga mereka mempunyai kompetensi dan kinerja yang lebih optimal. 
Tabel 4. Hasil Perbandingan pretest \& posttest Layanan dan Kinerja Guru BK berbasis analisis flop smart

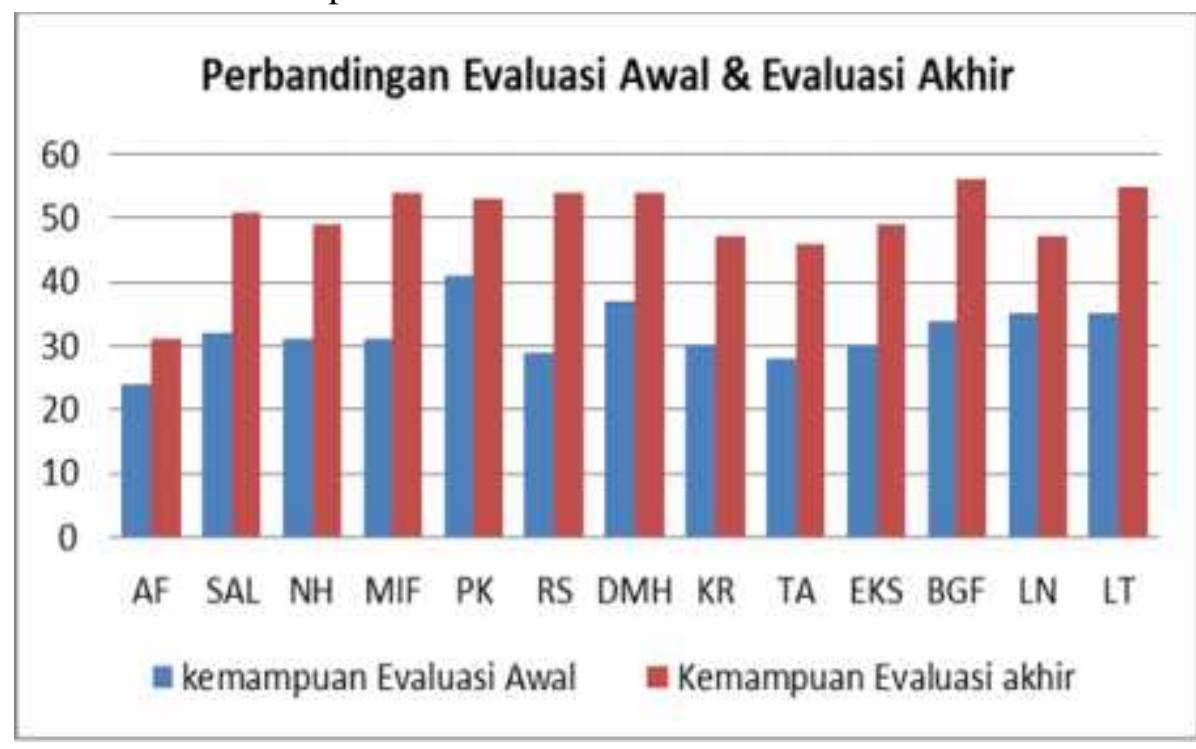

Berdasarkan data angket pasca kegiatan PKU yang diisi 13 peserta menunjukkan keterserapan akhir tentang layanan BK berbasis analisis flop smart dalam peningkatan kinerja dan kompetensi guru BK. Rata-rata persentase kenaikan keterserapan akhir sebesar $35 \%$ menunjukkan secara rata-rata meningkat apabila dibandingkan dengan katerserapan awal peserta. Ini berarti bahwa pelatihan ini cukup efektif untuk meningkatkan layanan, kompetensi dan kinerja guru BK dalam penggunaan layanan BK berbasis analisis flop smart dalam proses pemberian layanan BK

Dari uraian di atas dapat disimpulkan bahwa kegiatan pelatihan yang telah dilaksanakan berhasil memenuhi tujuannya. Tidak ada hambatan yang berarti dalam pelaksanaan kegiatan, baik dalam persiapan maupun dalam pelaksanaan kegiatan pelatihan.

Tabel 5. Hasil Peningkatan Kemampuan Layanan dan Kinerja Guru BK Berbasis Flop Smart

\begin{tabular}{|c|c|c|c|c|c|c|c|c|c|}
\hline \multirow[t]{2}{*}{ NO } & INISIAL & \multicolumn{2}{|c|}{ NILAI } & \multirow[b]{2}{*}{ KET } & \multirow[b]{2}{*}{ EV 2} & \multirow[b]{2}{*}{$\%$} & \multirow[b]{2}{*}{ KET } & \multirow[t]{2}{*}{ PERUBAHAN } & \multirow[t]{2}{*}{$\%$} \\
\hline & & EV 1 & $\%$ & & & & & & \\
\hline 1 & $\mathbf{A F}$ & 24 & 43 & rendah & 31 & 55 & rendah & 7 & 22.6 \\
\hline 2 & SAL & 32 & 57 & rendah & 51 & 91 & tinggi & 19 & 37.3 \\
\hline 3 & NH & 31 & 55 & rendah & 49 & 88 & tinggi & 18 & 36.7 \\
\hline 4 & MIF & 31 & 55 & rendah & 54 & 96 & tinggi & 23 & 42.6 \\
\hline 5 & PK & 41 & 73 & sedang & 53 & 95 & tinggi & 12 & 22.6 \\
\hline 6 & $\mathbf{R S}$ & 29 & 52 & rendah & 54 & 96 & tinggi & 25 & 46.3 \\
\hline 7 & DMH & 37 & 66 & sedang & 54 & 96 & tinggi & 17 & 31.5 \\
\hline 8 & KR & 30 & 54 & rendah & 47 & 84 & sedang & 17 & 36.2 \\
\hline 9 & TA & 28 & 50 & rendah & 46 & 82 & sedang & 18 & 39.1 \\
\hline 10 & EKS & 30 & 54 & rendah & 49 & 88 & tinggi & 19 & 38.8 \\
\hline 11 & BGF & 34 & 61 & sedang & 56 & 100 & tinggi & 22 & 39.3 \\
\hline 12 & $\mathbf{L N}$ & 35 & 63 & sedang & 47 & 84 & sedang & 12 & 25.5 \\
\hline \multirow[t]{2}{*}{13} & LT & 35 & 63 & sedang & 55 & 98 & tinggi & 20 & 36.4 \\
\hline & rata- rata & 32.08 & 57.28 & & 49.69 & 88.74 & & 18 & 35.0 \\
\hline
\end{tabular}




\section{SIMPULAN DAN SARAN}

Berdasarkan refleksi hasil kegiatan yang telah dilakukan, maka dapat ditarik beberapa kesimpulan sebagai berikut:

a. Layanan BK Berbasis Flop Smart lebih mudah di praktekkan dan hasilnya dapat digunakan untuk mengetahui siapa saja yang kurang disenangi, disenangi, serta populer dalam suatu kelompok.

b. Pentingnya kinerja Guru BK dalam pemanfaatan aplikasi komputer dalam rangka proses pembelajaran dan kompetensi guru BK, karena pada hakikatnya pelayanan kepada peserta didik tidak hanya secara klasikal saja tetapi juga harus tersedia alat instrumen pendukung dalam bentuk flop smart.

c. Guru BK dapat mengoptimalkan Layanan BK Berbasis Flop Smart untuk meningkatkan mutu pelayanan kepada siswa dan mempermudah pengelolaan administrasi dengan mengeksplorasi software yang belum banyak digunakan..

\section{UCAPAN TERIMAKASIH}

Ucapan terimakasih disampaikan kepada 1) Drs. Tawil, M.Pd., Kons. Yang selalu senantiasa memberikan arahan serta bimbingannya dalam proses pelaksanaan program kemitraan universitas, 2) Kepada Bapak/ Ibu Guru BK SMK di Kabupaten Magelang yang telah bersedia mengikuti pelatihan dan motivasi yang sangat luarbiasa mengikuti sesi demi sesi yang dilaksanakan., 3) Kepada LP3M Universitas Muhammadiyah Magelang yang telah memberikan kepercayaan kepada tim berkaitan dengan dana, fasilitas, bahan, atau saran.

\section{DAFTAR PUSTAKA}

Adhikrist Soetrysno Agrapatria, Frederik Samuel Papilaya, Michael Bezaleel Wenas, (2016), Perancangan dan Implementasi Aplikasi Pelaporan Perkebunan Berbasis Webgis Menggunakan Google Fusion dan Open Data Kit, (Universitas Kristen Satya Wacana, Semarang, Indonesia). http://repository.uksw.edu/handle/1234567 89/11238.
Bayu Febriadi, (2017), Sosialisasi Dan Pelatihan Aplikasi Google Form Sebagai Kuisioner Online Untuk Meningkatkan Kualitas Pelayanan, (Universitas Lancang Kuning, Riau, Indonesia).

Erwin Setiawan Panjaitan, Fitri Aryanti, (2016), Analisis Faktor- Faktor yang Mempengaruhi Minat Menggunakan Portal Akademik di Kalangan Mahasiswa Studi Kasus : Fakultas MIPA USU, (STMIK Mikroskil, Medan, Indonesia), Vol. 17, No. 2, (259-268). https://mikroskil.ac.id/ejurnal/index.php/js $\mathrm{m} /$ article/view/385.

Hamdan Husein Batubara, (2016), Pengunaan Google Form Sebagai Alat Penilaian Kinerja Dosen di Prodi PGMI UNISKA Muhammad Arsyad Al Banjari, (Universitas Islam Kalimantan, Banjarmasin, Indonesia).

Khanna Tiara, (2016), Pemanfaatan Google Scholar Dan Citation Dalam Memenuhi Kebutuhan Pembuatan Skripsi Mahasiswa Pada Perguruan Tinggi ,( Stmik Raharja, Tangerang, Indonesia). Vol.1, No. 1, (95113).http://ijc.ilearning.co/index.php/T MJ/article/view/28.

Rivort Pormes, Wiranto Herry Utomo, (2015), Analisis Perbandingan Cloud Document Pada Eyeos dan Google Docs, (Semarang, Indonesia), Vol. 5, No. 1, (087-4685). http://www.jsiskom.undip.ac.id/index.php/ jsk/article/view/77.

Untung Rahardja, Khanna Tiara, Ray Indra Taufik Wijaya, (2014), Penerapan Rinfo Sebagai Media Pendukung Untuk Proses Pembelajaran Pada Perguruan Tinggi Raharja (STMIK Raharja, Tangerang, Indonesia), Vol. 8, No. 1, (1978 - 8282).

Yustiandi, Duden Saepuzaman (2017), Virtual Assesment : Penilaian Siswa pada Kurikulum 2013 Menggunakan Aplikasi Google Forms, (Universitas Sultan Ageng Tirtayasa, Serang, Indonesia. 